Revista Complutense de Educación

ISSNe: 1988-2793

http://dx.doi.org/10.5209/RCED.52417

\title{
Vivir en Internet: Retos y reflexiones para la educación
}

Autores: Juan Luis Fuentes, Francisco Esteban y Carmen Caro

Editorial: Síntesis

Año de publicación: 2015

$N^{a}$ de páginas: 156

ISBN: 978-84-9077-174-7

Hace escasos años en una entrevista televisiva, un afamado cantante argentino, a colación de la difusión que tienen las redes sociales y cuánto han influido éstas en las relaciones humanas, decía que lo que no le gustaba de ellas era que por muchos amigos o seguidores que se tuvieran, si se va la luz de tu domicilio, esos "amigos" desaparecen. Hoy sucede lo mismo con la batería del teléfono móvil. En efecto, en nuestros días ha surgido una nueva neurosis social que ataca a lo más interno del homo tecnologicus creando síntomas elevados de ansiedad por la imposibilidad de comunicación entre personas.

Vivir en internet, este es el título del libro que nos ocupa y que con acierto, en estas tres palabras, recoge algo más que una realidad social, una realidad que requiere de atención sostenida y pormenorizada desde la educación para con la misma. El uso de internet no es ya una realidad como tal sino una necesidad, y este es el punto de partida del ensayo, el cual se estructura en cinco apartados mediante los cuales los autores nos acercan el panorama actual y las expectativas que el mismo refleja desde el ámbito pedagógico. El tono y los recursos utilizados por los autores son de carácter filosófico si bien es cierto tanto el léxico como su coherencia interna y linealidad acercan las reflexiones a un público diverso, tanto general como especializado.

Tras el cuidado prólogo elaborado por el Catedrático José Antonio IbáñezMartín, y la pertinente introducción, el primer capítulo $<<$ Vivir en internet $>>$ expone someramente los grandes cambios que las TIC han ocasionado en lo que a la realidad más próxima se refiere. En el contexto pedagógico éstos se han orientado fundamentalmente hacia la optimización del proceso educativo. En este sentido es necesario destacar aquellas parcelas que incumben a la vida en la red y que configuran los subapartados de este primer capítulo, a saber: Viejas adicciones, nuevos problemas, Intimidad e internet, Internet y nivel académico, Profesores y redes sociales, Información y verdad y por último, Ciberbullying y violencia. ¿Qué posibilidades dispone la educación en nuestros días para atender a la vida en internet? ¿Cómo es verdaderamente la vida en internet de los jóvenes en nuestro país? ¿Es la red un espacio peligroso y desatendido por padres y profesores? Cuestiones, entre otras tantas, que son respondidas en los siguientes apartados del ensayo. 
El segundo capítulo $<<$ La vida en internet $>>$ presenta un interesante estudio nacional elaborado con adolescentes de diversas comunidades autónomas española. Resulta conveniente detenerse en el mismo, pues sus resultados, estructuran los dos capítulos posteriores. En este sentido, aspectos como la percepción de sentirse enganchado a internet dispone de una ponderación del 46,5\% de la muestra. Junto a este dato, se observa que la nota media es peor en aquellos alumnos que confiesan permanecer más horas conectados, viéndose incrementada la dedicación a internet a medida que la edad avanza. De otra parte, destaca también el elevado porcentaje de estudiantes $(55,11 \%)$ que no considera que aquello que publica en la red tenga consecuencias para su futuro. Sobre los beneficios que les plantea la red, se observa a partes iguales el hecho de que les permite ser más sociables, estar de buen humor y comunicarse con un compañero o amigo. Asimismo, los resultados reflejan que 7 de cada 10 alumnos miente en su perfil de internet. Datos muy similares se obtuvieron sobre la cuestión de si habían visto a algún amigo enviar mensajes dañinos a otras personas $(45,6 \%)$. Por último, no deja de sorprender el $21,1 \%$ de los alumnos que afirman haber recibido una petición de foto comprometida, pero no es menos sorprendente el dato de que sólo el $15,7 \%$ de los alumnos encuestados, acudiría a sus padres ante una situación de ciberacoso.

Tras lo expuesto en la investigación, el tercer bloque temático nos acerca $<<$ Las bondades de vivir en internet $>>$ mediante el cual los autores, a la luz de los datos resultantes, filtran la información para entresacar, la parte positiva de la vida en internet. Tras ello puede extraerse la afirmación de que la vida en internet presenta aspectos positivos y a su vez contempla grandes oportunidades de crecimiento: "vivir en internet no es necesariamente malvivir, sino que también puede ser una vida llena de oportunidades y de buenas prácticas susceptible de conducir a un óptimo desarrollo personal" (p. 99).

A continuación, el capítulo titulado $<<$ Las desventuras de vivir en internet $>>$ de forma antónima al capítulo anterior, se centra en los aspectos más negativos del estudio realizado. A pesar de que previamente se extraía la síntesis de que los datos eran esperanzadores, $\mathrm{y}$, hasta cierto punto, positivos, los mismos también reflejan la necesidad de atención específica y detenida sobre los fines de internet, subrayando a su vez la necesidad de desarrollar una mejor formación que posibilite así mismo una más meticulosa discriminación de la información existente, una específica y más adecuada gestión de la identidad digital.

En última instancia, y como cierre del ensayo, se estructura el quinto apartado bajo el título $<<$ Las esperanzas de vivir en internet $>>$. Este epígrafe final desglosa detenidamente diversos aspectos que a juicio de los autores posibilitarían una vida en internet acorde a las necesidades y retos que hoy plantea la vida digital. Es interesante la alusión realizada al cuidado de la intimidad en internet, aspecto que no pasa desapercibido en nuestros días debido a la multitud de plataformas y la inmensidad de soportes que permiten conexión entre usuarios. Hoy, las personas comparten todo tipo de información personal de manera, perdiendo cualquier posible pudor en favor de la comunicación y expansión de sus vivencias, apoyándose en la distancia y anonimato que la propia red permite. Resulta interesante el concepto propuesto en este sentido, a saber, la virtud del pudor, que sin duda puede parecer lejos de ser considerada en nuestros días mas a juicio de los autores debiera ser atendida pedagógicamente como marco de referencia personal 
que posibilite un adecuado desarrollo integral de la persona. A continuación se realiza un análisis sobre la potencialidad educativa de las narrativas transmedia, las cuales permiten no sólo la diversidad de experiencias sino la interconexión de las mismas, el desarrollo de capacidades específicas así como la posible promoción de aprendizajes ético-cívicos basados en ellas.

En síntesis es este un ensayo coherente y esclarecedor que cumple su objetivo: reflexionar sobre la vida en internet de un modo educativo y postular diversos escenarios de actuación desde el ámbito pedagógico. Los bloques capitulares presentan una consistencia reflexiva pertinente $\mathrm{y}$, lo que es más importante, mantienen una línea argumental que posibilita sobremanera la reflexión educativa sobre la realidad que supone el hecho de vivir en internet hoy, interpelando a la sociedad y, más concretamente, a todos los agentes educativos a situarse a la altura de este gran reto.

Javier Bermejo Fernández-Nieto Universidad Complutense de Madrid javiberme@hotmail.com 